\title{
O ALEITAMENTO MATERNO NO CÁRCERE À LUZ DO ESTATUTO DA CRIANÇA E DO ADOLESCENTE
}

BREASTFEEDING IN CARCERE AND THE STATUTE OF CHILDHOOD AND THE ADOLESCENCE

\section{Luiz Paulo Dammski', Izadora Caroline Costa ${ }^{2}$}

ENVIADO EM: 31/03/2020 | ACEITO EM: 03/06/2020

DOI: $10.5902 / 2317175843223$

\section{RESUMO}

A pesquisa desenvolvida pretende abordar o direito ao aleitamento materno no cárcere frente às dificuldades para a sua implementação no atual contexto prisional brasileiro, marcado pela insalubridade e pela grande violação de direitos. Neste cenário, vislumbra-se a necessidade de se refletir acerca das estruturas prisionais voltadas à população feminina, em especial para gestantes e parturientes, em cotejo com a análise do papel do Estado para a implementação de políticas eficazes para a proteção da maternidade e da criança, observados os preceitos protetivos nacionais e internacionais.

Palavras-Chave: Aleitamento materno; Amamentação no cárcere; Proteção integral da criança; Estatuto da Criança e do Adolescente.

1 Professor Adjunto da Fundação de Estudos Sociais do Paraná - FESP - PR e Professor Adjunto do Instituto Superior do Litoral do Paraná - ISULPAR Mestre em Direito (Direitos Fundamentais e Democracia) pelo Centro Autônomo Universitário do Brasil (UNIBRASIL). Graduado em Direito pela Universidade Federal do Paraná (UFPR). 2 Conciliadora e Mediadora extrajudicial e judicial, formada pelo CNJ (2019), IMAB (2018) e APRTF (2018). Estagiária no Ministério Público do Estado do Paraná (MPPR). Graduada em Direito pelo Centro Universitário Autônomo do Brasil (UniBrasil). Pós-Graduanda em direito Constitucional na ABDCONST. 


\section{ABSTRACT}

The research developed in the article intends to approach the right to breastfeeding in jail, contrasting this prerogative with the difficulties of its implementation in the Brazilian prison context, marked by the unhealthy conditions of its institutes and the violation of civil rights. Taking this scenario in account, it turns out that it is necessary to rethink the structures of the feminine prison system, especially for pregnant and parturient women. In this sense, it is relevant to think about the role of the State in the implementation of effective public policies related to the protection of the maternity and the childhood, taking into account the national and international precepts.

Keywords: Breastfeeding; In jail breastfeeding; Integral protection of the child; Statute of the Childhood and the Adolescence.

\section{Introdução}

O direito à amamentação no cárcere afigura-se como uma garantia fundamental prevista na Constituição Federal e assegurada por diversos dispositivos infraconstitucionais e tratados internacionais. Apesar da vasta gama de direitos atrelados à maternidade no cárcere, as estruturas prisionais não são adequadas ao recebimento de gestantes e parturientes, especialmente devido à precariedade da sua infraestrutura. As prisões destinadas às mulheres normalmente não possuem características físicas necessárias para o recebimento da população feminina e, tampouco, para o recebimento de gestantes e crianças.

Além das mais variadas circunstâncias de carência física dos estabelecimentos prisionais, especialmente no que tange a condições mínimas de salubridade, a falta de creches, de berçários e de locais adequados para o convívio entre mãe e filho culminam na rotineira violação de direitos ligados à proteção da maternidade e da infância.

Dentre o espectro de relações maternais, o aleitamento materno se mostra como uma das mais relevantes para o desenvolvimento dos laços entre mãe e filho. Justamente por conta de sua relevância, a amamentação se constitui em uma questão de direitos humanos tanto para a criança e quanto para a mãe, e está intrinsecamente ligado à ideia de dignidade. A privação do aleitamento ou a sua realização em condições inadequadas - ou mesmo insalubres, como sói ocorrer - representa uma ofensa à dignidade daquele indivíduo que acaba de iniciar sua vida.

Além do aleitamento materno e do convívio familiar, condições adequadas de habitação e de vivência para a mãe e para o bebê são essenciais para a concretude da dignidade da pessoa humana e para a efetivação de outros direitos igualmente caros à infância e à maternidade.

Nesta perspectiva, cabe aos Estados a introdução de instrumentos eficazes para o apoio, proteção e fomento ao aleitamento materno digno, proporcionando condições mínimas para o exercício da maternidade - ainda que no cárcere. A melhoria nas condições carcerárias, portanto, depende de ações 
governamentais eficientes - verdadeiras políticas públicas -, que assegurem os direitos humanos e proporcionem o desenvolvimento da proteção integral, da saúde e da dignidade da criança e da mãe.

\section{0 direito fundamental ao aleitamento materno no cárcere sob a perspectiva dos direitos humanos}

A amamentação no cárcere é um direito e uma garantia fundamental que assegura às presidiárias condições para que possam permanecer com seus filhos durante o período de amamentação, conforme disposição do artigo $5^{\circ}$, inciso L, da Constituição Federal. Neste sentido, o aleitamento materno compreende tanto o direito da detenta em amamentar o seu filho quanto a garantia da criança em receber o leite materno, que é essencial para a sua subsistência e o desenvolvimento sadio (DIAS e BRAZ, 2017, p. 98).

Além de guarida em âmbito constitucional, o direito ao aleitamento está assegurado, ainda, na Lei de Execuções Penais - LEP. A LEP determina que os estabelecimentos prisionais destinados a mulheres sejam dotados de berçário e de locais em que as condenadas possam cuidar de seus filhos, inclusive amamentá-los, no mínimo, até os 6 (seis) meses de idade, consoante ao artigo 82 , parágrafo $\S 2^{\circ}$, da referida lei.

No mesmo sentido, o Conselho Nacional de Política Criminal e Penitenciária - CNPCP, por intermédio da Resolução no 14 de 1994, estipula que as entidades prisionais proporcionem opções para que a população carcerária feminina possa permanecer com os seus filhos durante o período de amamentação. ${ }^{3}$

Para que o direito à amamentação seja assegurado de forma mais eficiente, o Estatuto da Criança e do Adolescente - ECA (Lei n. 8.069/1990) dedicou capítulo exclusivo à regulamentação do direito à vida e à saúde, dotado de características específicas para a sua tutela. Visando à proteção integral da criança, o ECA impõe que o Poder Público e as instituições proporcionem condições adequadas ao aleitamento materno, inclusive aos filhos de mães submetidas a medida privativa de liberdade, por intermédio de ambiência que atenda às normas sanitárias e assistenciais, visando ao desenvolvimento integral da criança que se encontra em acolhimento com a sua genitora, de acordo com a redação do artigo $8^{\circ}$, § $10^{\circ}$ e caput do artigo $9^{\circ}$.

Em razão da relevância da amamentação, o ECA determina ainda, em seu artigo $8^{\circ}, \S 7^{\circ}$, que a gestante tem o direito receber orientação sobre aleitamento materno e sobre crescimento e desenvolvimento infantil, bem como sobre formas de favorecer a criação de vínculos afetivos e de estimular o desenvolvimento integral da criança.

3 Art. $7^{\circ}$. "Presos pertencentes a categorias diversas devem ser alojados em diferentes estabelecimentos prisionais ou em suas seç̃es, observadas características pessoais tais como: sexo, idade, situação judicial e legal, quantidade de pena a que foi condenado, regime de execução, natureza da prisão e o tratamento específico que lhe corresponda, atendendo ao princípio da individualização da pena". $§ 2^{\circ}$. "Serão asseguradas condições para que a presa possa permanecer com seus filhos durante o período de amamentação dos mesmos. Conselho Nacional de Política Criminal e Penitenciária" (CNPCP, 1994). 
Aliadas às regras nacionais, existem diversas normativas internacionais que asseguram a amamentação no cárcere, como as Regras das Nações Unidas para o tratamento de mulheres presas e medidas não privativas de liberdade para mulheres infratoras, também denominadas de Regras de Bangkok, criadas em 2010 pela Assembleia Geral da Organização das Nações Unidas - ONU. As Regras de Bangkok têm como objetivo proporcionar uma visão multidisciplinar para as especificidades de gênero no encarceramento feminino, em especial no que diz respeito às mulheres grávidas.

A partir da disposição 48 das Regras de Bangkok, prevê-se a exigência de que os estabelecimentos penitenciários devem contar com instalações especiais para as mulheres grávidas e em estado puerpério. Nesta mesma normativa prevê-se, ainda, que as mulheres gestantes e lactantes têm o direito de receber orientações sobre dieta e saúde, ser estimuladas à amamentação de seus filhos e ter o máximo possível de oportunidades de passar tempo com eles (ONU, 2010).

A Organização Mundial da Saúde - OMS, também denominada World Health Organization, impôs diretrizes para o aleitamento materno em circunstâncias de cárcere, por intermédio da publicação do material "Guideline: Protecting, promoting and supporting breastfeeding in facilities providing maternity and newborn services", no ano de 2017.

Nesta publicação a OMS dispõe que as crianças têm direito à vida, à sobrevivência e ao desenvolvimento, no maior nível de saúde possível. $\mathrm{O}$ atingimento de níveis minimamente satisfatórios de desenvolvimento infantil depende sobretudo da amamentação, considerada um componente integral para a promoção destes direitos (WHO, 2017).

As orientações da OMS confirmam a premissa básica de que o aleitamento materno é uma questão de direitos humanos tanto para a criança e quanto para a mãe, cabendo, nesta perspectiva, aos Estados a introdução de instrumentos eficazes para o apoio, proteção e fomento à amamentação (WHO, 2017).

A Convenção sobre os Direitos da Criança (1990) ressalta a preocupação com o quadro nutricional das crianças, preconizando a necessidade de difusão do conhecimento sobre saúde e nutrição infantil, em especial pelas vantagens do aleitamento materno. No mesmo sentido, o Pacto Internacional sobre os Direitos Econômicos, Sociais e Culturais (1966) trata do direito à alimentação adequada, abordando a relevância da ingestão de nutrientes para o crescimento físico e mental e para o desenvolvimento. Por esta razão, se mostra essencial a adoção de medidas para fortalecer padrões de alimentação adequados, incluindo o aleitamento materno.

Diante deste panorama de normas e recomendações, verifica-se o relevante papel do Estado na garantia e na efetivação destes caríssimos direitos de mães em situação de cárcere e seus filhos, de modo a proporcionar condições mínimas para o exercício da maternidade e para a proteção integral da criança, especialmente por intermédio da amamentação e do convívio familiar. 


\title{
3 A importância da amamentação para o desenvolvimento infantil
}

A amamentação é fundamental para a proteção integral da criança, uma vez que o aleitamento materno constitui a maior fonte de nutrição e possui todas as propriedades necessárias para o crescimento e desenvolvimento saudável do bebê (DIAS e BRAZ, 2017, p. 98).

Em razão da relevância do aleitamento para o desenvolvimento da criança, o Ministério da Saúde recomenda que este seja realizado até os dois anos de idade, devendo ocorrer de modo exclusivo pelo menos até os seis meses da criança (MS, 2015). O aleitamento exclusivo é aquele em que a alimentação da criança ocorre somente pelo leite materno ou leite humano de outra fonte, ou seja, a alimentação não é compartilhada com nenhum outro tipo de alimento (ABRINQ, 2017).

O leite materno é composto por cerca de 160 substâncias, contendo proteínas, gorduras e carboidratos que possibilitam a criação de anticorpos, o ganho de peso e o desenvolvimento adequado das funções físicas e cognitivas da criança (DALMÁCIO et al., 2014, p. 56). A amamentação, portanto, proporciona fonte de energia e aumento da capacidade cognitiva, favorecendo a inteligência e o desenvolvimento social, pois os cuidados iniciais, nos primeiros anos de vida, são essenciais para saúde e para o desenvolvimento das aptidões da criança (FREIRE, 2017, p. 26). Nesta perspectiva, o Ministério da Saúde enfatiza a relevância do caráter nutritivo do leite materno:

\begin{abstract}
Por ser da mesma espécie, o leite materno contém todos os nutrientes essenciais para o crescimento e o desenvolvimento ótimos da criança pequena, além de ser mais bem digerido, quando comparado com leites de outras espécies. O leite materno é capaz de suprir sozinho as necessidades nutricionais da criança nos primeiros seis meses, e continua sendo uma importante fonte de nutrientes no segundo ano de vida, especialmente de proteínas, gorduras e vitaminas (MS, 2015).
\end{abstract}

Em razão de seu caráter nutritivo, o aleitamento materno possui papel fundamental na prevenção de doenças e na redução de morbidades e mortalidade infantis. Assim, o aleitamento previne a ocorrência de diversas doenças, como otites, meningites, vômitos, diarreia, pneumonia, diabete, doenças cardiovasculares, desordens do sistema imunológico (alergias, doenças inflamatórias intestinais), doença celíaca e, ainda, alguns tipos de cânceres (DALMÁCIO et al., 2014, p. 56). Ademais, o aleitamento contribui para a redução da obesidade infantil, pois auxilia na regulação do metabolismo da criança e melhora a sua nutrição em diversos aspectos (ABRINQ, 2019).

A título de exemplificação, no concernente a doenças infecciosas, o Ministério da Saúde evidencia que crianças não amamentadas têm um risco três vezes maior de desidratarem e de morrerem por diarreia quando comparadas 
com crianças que obtiveram aleitamento materno adequado. No caso de doenças respiratórias foi constatado que o risco de hospitalização por bronquiolite foi sete vezes maior em crianças amamentadas por tempo menor do que o indicado. Em relação à obesidade, por sua vez, foi constatado que o sobrepeso de crianças maiores de 3 anos decorre principalmente do tipo de alimentação empregado nos primeiros anos de vida (MS, 2015).

Além disso, a amamentação na infância é a forma mais sensível, econômica e eficaz de prevenção da mortalidade infantil (DALMÁCIO et al., 2014, p. 56). De acordo com o estudo realizado pela Fundação ABRINQ sobre o Cenário da infância e adolescência no Brasil, no ano de 2019, foi constatado que a maior taxa de mortalidade infantil compreende os menores de um ano de idade. Todavia, as reduções de mortes nesta faixa etária são evitáveis especialmente por intermédio de políticas de apoio à mulher na gestação e no parto e ao recém-nascido (Figura 1), conforme se verifica no gráfico a seguir:

Figura 1 - Causas evitáveis de mortalidade infantil por região

\section{Proporção de óbitos de crianças menores de um ano de idade por causas evitáveis segundo grupos de causas e Grandes Regiöes - 2017}

Reduziveis por atenção à mulher na gestação, parto ou ao recém-nascido

Reduziveis por açōes de diagnóstico e tratamento adequados

Reduziveis por açōes de promoção à saúde

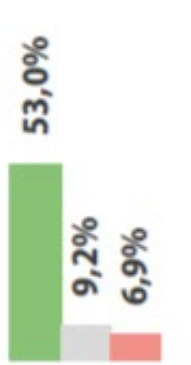

各

ผั กิ

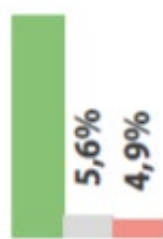

응

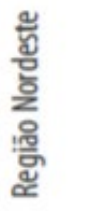

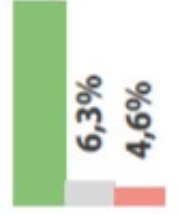
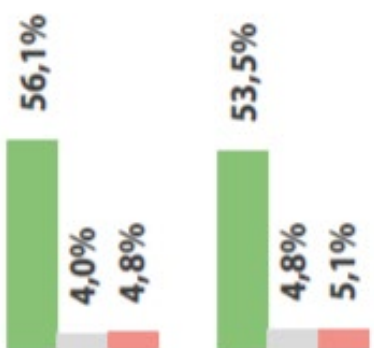

ํํํ

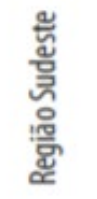

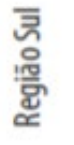

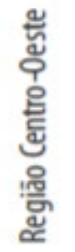

Fonte: Cenário da infância e adolescência no Brasil (ABRINQ, 2019). ${ }^{4}$

Assim, verifica-se que o incentivo ao aleitamento materno é essencial para a redução das taxas de mortalidade e para a melhoria no quadro nutri4 O estudo da ABRINQ utilizou os dados do Ministério da Saúde, da Secretaria de Vigilância em Saúde, da Diretoria de Apoio Administrativo ao Sistema de Saúde, do Ministério da Saúde, da Secretaria de Vigilância em Saúde, da Coordenação-Geral de Informações e Análises Epidemiológicas e do Sistema de Informações sobre Mortalidade para a elaboração do gráfico (ABRINQ, 2019). 
cional das crianças brasileiras (ABRINQ, 2019), reverberando, evidentemente, a melhora das condições materiais de desenvolvimento da criança. Apesar de todos os benefícios envolvidos no processo de amamentação, o aleitamento de crianças menores de 6 meses de idade (180 dias) no Brasil ocorre aquém do recomendado, pois a média nacional é de cerca de 41\% (MS, 2009).

Nos países desenvolvidos a diminuição da mortalidade infantil ocorreu por meio de fatores exógenos e, portanto, passíveis de prevenção, como condições adequadas de pré-natal e melhoria nas condições do parto (PAIXÃO e FERREIRA, 2012, p. 07). Neste contexto, projeções realizadas pela OMS e pela UNICEF demonstram que cerca de 6 milhões de crianças deixam de morrer anualmente em função do aleitamento materno exclusivo (ABRINQ, 2017). O Ministério da Saúde estima também que a amamentação poderia evitar aproximadamente $13 \%$ das mortes em crianças menores de 5 anos, diante da implementação de ações preventivas, e considera que nenhuma outra ação isolada teria o condão de alcançar o impacto que a amamentação tem na redução da mortalidade infantil (MS, 2015).

Além de repercutir na saúde e nas capacidades materiais de desenvolvimento do infante, o aleitamento materno auxilia no desenvolvimento afetivo, o que se dá por intermédio da formação do vínculo entre a mãe o bebê, proporcionando afeto e proteção à criança. Neste sentido, o contato físico entre a genitora e a criança favorece a criação de laços e reduz a possibilidade de rejeição e de abandono (FREIRE, 2017, p. 27).

Acerca da importância do vínculo afetivo na primeira infância, Leal aduz que:

A relação primária entre pais e bebê, especificamente com a mãe, é amplamente relacionada à sobrevivência da criança e parecem gerar estimulações recíprocas relevantes para o estabelecimento de comportamentos, maternais e infantis, adequados. Neste período, o contato físico da mãe com seu bebê, o mantém numa situação de conforto e segurança, fornecendo a base segura a partir do qual o mesmo explorará o ambiente em seu entorno $(2018$, p. 27).

Além de benefícios para a criança, o aleitamento também traz consequências favoráveis para a mãe, pois diminui as chances de hemorragias pós-parto, ajuda na recuperação do peso, diminui o risco de câncer de mama, ovário e endométrio, bem como auxilia no retardamento da ovulação - que reduz a probabilidade de uma nova gestação a curto prazo (DALMÁCIO et al., 2014, p. 56).

Estudos apontam a redução no desenvolvimento de câncer de mama de cerca de $4,3 \%$ a cada 12 meses de duração de amamentação. A eficácia contraceptiva, no entanto, se constitui um excelente método de prevenção nos primeiros seis meses após o parto, tendo aproximadamente $98 \%$ de eficácia (MS, 2015). 
Como a convivência com o bebê constitui uma fonte de afeto dentro das instalações carcerárias, a relação mãe-filho acaba por repercutir de forma positiva no processo de ressocialização das detentas (LEAL, 2018, p. 21). No mesmo entendimento, o Ministério da Saúde ressalta a importância do processo interativo entre mãe e filho:

Amamentar é muito mais do que nutrir a criança. É um processo que envolve interação profunda entre mãe e filho, com repercussões no estado nutricional da criança, em sua habilidade de se defender de infecções, em sua fisiologia e no seu desenvolvimento cognitivo e emocional, e em sua saúde no longo prazo, além de ter implicações na saúde física e psíquica da mãe (...) Uma amamentação prazerosa, os olhos nos olhos e o contato contínuo entre mãe e filho certamente fortalecem os laços afetivos entre eles, oportunizando intimidade, troca de afeto e sentimentos de segurança e de proteção na criança e de autoconfiança e de realização na mulher. Amamentação é uma forma muito especial de comunicação entre a mãe e o bebê e uma oportunidade de a criança aprender muito cedo a se comunicar com afeto e confiança (MS, 2015).

Em razão dos benefícios mútuos que a amamentação proporciona, Freire $(2017$, p. 27) entende que "diante de tantos benefícios, a amamentação tornou-se um direito da mulher e um componente fundamental para assegurar o direito da criança ao alimento, à saúde e ao cuidado".

Por outro lado, a ausência de amamentação e de contato com a criança pode culminar no surgimento de problemas de saúde de ordem física e psíquica, além de contribuir para a fragilização familiar, pois dificulta a manutenção dos vínculos da mãe com o bebê (ZANINELLI, 2015, p. 99). Assim, em decorrência do vínculo estabelecido entre a criança e a mãe desde a gestação, a importância da amamentação para a saúde do bebê e o papel da genitora como cuidadora primária justificam a garantia da convivência dentro das unidades prisionais (CARNEIRO e VERÍSSIMO, 2016, p. 44).

Apesar da vasta gama de direitos assegurados à mulher e à criança no cárcere, na prática, a realidade brasileira não proporciona condições materiais adequadas ao exercício destes direitos, violando não apenas normas nacionais e internacionais, como dificultando a própria ressocialização das detentas e gerando prejuízos à saúde física e psíquica dos próprios filhos de mulheres encarceradas.

A precariedade das estruturas prisionais, especialmente no que toca à geração de condições mínimas de interação entre mãe e filho para fins de amamentação, gera diversos prejuízos e fere direitos de ambas as partes (ZANINELLI, 2015, p. 99). Neste contexto, verifica-se a imprescindibilidade da adoção de políticas públicas orientadas a melhorar as condições do ambiente prisional para assegurar o desenvolvimento integral da criança e a efetivação dos direitos humanos e da dignidade da pessoa humana de ambos os polos envolvidos nesta relação - mãe e filho. 


\section{Considerações sobre a infraestrutura das unidades prisionais femininas e o princípio da proteção integral da criança}

O encarceramento feminino é um fenômeno que tem aumentado significativamente no Brasil, trazendo impacto para as políticas de segurança e administração penitenciária, assim como para as políticas específicas de gênero. $O$ ingresso de mulheres no sistema prisional brasileiro é habitual e vem crescendo em números absolutos ao longo dos anos. Ainda assim, prisões destinadas às mulheres não abarcam características e particularidades necessárias para o recebimento da população feminina com atenção a questões de ordem familiar (CNJ, 2019).

O último Levantamento Nacional de Informações Penitenciárias - INFOPEN, realizado pelo Departamento Penitenciário Nacional do Ministério da Justiça e Segurança Pública em 2019, constatou que 752.277 pessoas estão privadas de liberdade no Brasil, sendo 715.138 (95,06\%) homens e 37.139 (4,94\%) mulheres. ${ }^{5}$ De todas as unidades prisionais cadastradas no INFOPEN, $83,62 \%$ são masculinas, $3,8 \%$ são femininas e outros $12,58 \%$ são destinadas a ambos os públicos (MJSP, 2019).

Historicamente, as políticas penais têm sido idealizadas para homens, deixando de lado as peculiaridades da realidade prisional feminina, como idade, identidade de gênero, gestação e maternidade (CNJ, 2019). A inadequação das unidades prisionais decorre, principalmente, do fato que muitas das prisões femininas existentes no Brasil foram originalmente construídas para o ingresso de presos do sexo masculino (ANTONINI, 2014, p. 112-117).

Em razão do número inferior de mulheres encarceradas em relação ao quantitativo de homens, os recursos estatais enviados para o sistema prisional são encaminhados prioritariamente para os presídios masculinos, ignorando as particularidades dos ambientes femininos. Em razão da inadequação das unidades prisionais femininas, Zaninelli aponta que a ausência de locais apropriados para a mulheres reafirma a desigualdade entre os sexos:

\footnotetext{
O fato das mulheres praticarem delitos em menor quantidade do que os homens sempre foi interpretado como menor potencial agressivo o que contribui para que o atendimento despendido as mulheres seja visto como mero complemento daquele despendido ao público masculino (...) A construção social existente a respeito dos papéis sociais a serem desempenhados por homens e por mulheres foi reproduzida de forma ainda mais perversa no sistema prisional e a realidade do sistema penitenciário brasileiro que custodia homens passou a ser ainda mais penosa quando o público alvo passou a ser composto também por mulheres infratoras (2015, p. 47).
}

Essa perspectiva afronta o direito fundamental disposto no artigo $5^{\circ}$,

5 População carcerária analisada no período de janeiro a junho do ano de 2019 (MJSP, 2019). 
LVIII, da Constituição Federal, que dispõe que "a pena será cumprida em estabelecimentos distintos, de acordo com a natureza do delito, a idade e o sexo do apenado", bem como não observa o disposto no artigo 37 do Código Penal, que determina "que as mulheres cumpram pena em estabelecimento próprio, observando-se os deveres e direitos inerentes à sua condição pessoal".

De acordo com a determinação da LEP, as penitenciárias femininas devem conter seção própria para gestante e parturiente, de acordo com o seu artigo 89. Contudo, além dos complexos prisionais serem notoriamente precários, no tocante às condições de habitabilidade, as unidades femininas não dispõem de espaços adequados para a saúde da mulher grávida, especialmente no que tange ao tratamento do pré-natal e pós-natal (DALMÁCIO et al., 2014, p. 57).

A ausência de acompanhamento adequado no pré-natal e no pós-parto contraria ainda as garantias previstas na LEP, que preceitua que "será assegurado acompanhamento médico à mulher, principalmente no pré-natal e no pós-parto, extensivo ao recém-nascido", consoante disposto no artigo 14, parágrafo $\S 3^{\circ}$, da referida lei.

A respeito da assistência à saúde gestacional no cárcere, Antonini preceitua que:

As reclusas não têm acesso a acompanhamento médico necessário e fundamental a saúde da mãe e do nascituro, além da total ausência de acompanhamento pré-natal, e, em muitos casos a não realização de exames fundamentais à constatação de doenças graves e sexualmente transmissíveis (2014, p. 112).

Acerca da estrutura prisional, foi averiguado que dentre o total de estabelecimentos femininos e mistos que albergam mulheres, apenas $16 \%$ das unidades possuem celas ou dormitórios adequados para gestantes, conforme os dados obtidos no INFOPEN Mulheres, no ano de 2018. Em relação à capacidade de oferecer espaço para o permanecimento materno com o filho, o estudo apontou que apenas $14 \%$ das unidades prisionais contam com berçário e/ou centro de referência materno-infantil, os quais compreendem os espaços destinados a crianças de até 2 anos de idade (MJSP, 2018).

Além de poucas unidades prisionais possuírem berçário ou centro de referência materno-infantil, as que possuem, muitas vezes, contam com acomodações instalações improvisadas, que albergam as mesmas características de insalubridade dos locais comuns (ZANINELLI, 2015, p. 103), de modo a reproduzir todos os riscos e aspectos negativos do restante do estabelecimento prisional.

No que toca à maternidade no cárcere, Carneiro e Veríssimo entendem que:

Acreditamos ser consenso que prisão não foi pensada para gestantes, tampouco para bebês. Por se tratar de um ambiente permeado de restrições, códigos de conduta, rotina bem definida e, acima de tudo, por se configurar em lugar tenso e violento, a 
prisão torna-se local de comprometimento a uma boa gestação e ao desenvolvimento infantil. Some-se o fato de que, no Brasil, as unidades prisionais apresentam falta de estrutura física, de mobiliário e insuficiente número de profissionais especializados para o atendimento a esse púbico (2016, p. 40).

A ausência de estímulo à amamentação, a impossibilidade material de contato efetivo entre mãe e filho, a inexistência de espaços de acolhimento e cuidado com criança no interior de estabelecimentos carcerários, bem como as diversas restrições que a rotina carcerária impõe às detentas culmina na mais absoluta redução de contato e interação maternal, repercutindo na ausência ou na ocorrência de aleitamento materno por um período muito inferior ao recomendado em lei (LEAL, 2018, p. 19-21). Ademais, em razão da precariedade estrutural carcerária, muitas mães costumam entregar as crianças para terceiros ou entidades de acolhimento após o nascimento (VIEIRA, 2013, p. 231).

Além do período de amamentação, a LEP assegura que as genitoras possam ficar com seus filhos até os sete anos de idade, devendo o estabelecimento prisional possuir creches para abrigá-los. As creches devem possuir atendimento pessoal qualificado, de acordo com as diretrizes adotadas pela legislação educacional, bem como garantir o horário de funcionamento que se adeque à melhor assistência à criança e à sua responsável, conforme disposição expressa do artigo 83 e 89 da referida lei.

A possibilidade de não separação entre mãe e filho evita que esta criança seja encaminhada a unidades de acolhimento - nos casos em que não é possível o seu encaminhamento para a família natural ou extensa - e mantém os vínculos de afinidade e afetividade, aspectos essenciais para o desenvolvimento da criança. Todavia, apesar de a família ser preservada, os direitos à cultura, esporte e lazer da criança ficam prejudicados e, em especial, o direito à educação, em razão das dificuldades na implementação de uma política de educação básica dentro de estabelecimentos prisionais (VIEIRA, 2013, p. 252262).

As creches prisionais são comumente diferentes das creches tradicionais, especialmente porque não possuem atividades pedagógicas adequadas e não contam com cuidadores especiais para a educação infantil, uma vez que as crianças são cuidadas pelas próprias mães (ARMELIN, 2010, p. 08).

As atividades pedagógicas, no entanto, são fundamentais para as interações e estímulos da criança, como sons, formas, cores e texturas, que são essenciais para as conexões cerebrais nos primeiros anos de vida e para o desenvolvimento de habilidades motoras, perceptivas, cognitivas, linguísticas e sociais (BRUSCATO; RANGEL, 2015, p. 406)

Não obstante o direito à amamentação e ao convívio familiar sejam assegurados em diversos dispositivos legais, a falta de creches, de berçários e de locais adequados para o recebimento de crianças violam e restringem esses direitos no campo material, reforçando a invisibilidade das mulheres e de seus 
bebês, configurando um cenário de exclusão (ZANINELLI, 2015, p. 100). Deste modo, as crianças já nascem em condições de absoluta indignidade, uma vez que, segundo Gominho (2016, p. 02) "não existe nenhuma preocupação com a salubridade do ambiente e com a importância dos vínculos afetivos que existem dentro da relação mãe-bebê", configurando verdadeira afronta ao princípio da proteção integral da criança.

A submissão de crianças a um ambiente penitenciário insalubre e estressante nos primeiros anos de vida pode comprometer o seu desenvolvimento pelo resto da vida (LEAL, 2018, p. 24). Deve-se destacar, neste sentido, que o desenvolvimento saudável das crianças possui preponderância no ordenamento jurídico pátrio, sendo assegurado no artigo $227, \S 1^{\circ}$, do texto constitucional:

Art. 227. É dever da família, da sociedade e do Estado assegurar à criança, ao adolescente e ao jovem, com absoluta prioridade, o direito à vida, à saúde, à alimentação, à educação, ao lazer, à profissionalização, à cultura, à dignidade, ao respeito, à liberdade e à convivência familiar e comunitária, além de colocá-los a salvo de toda forma de negligência, discriminação, exploração, violência, crueldade e opressão

$\S 1^{\circ}$ Todas as oportunidades e facilidades, a fim de lhes facultar o desenvolvimento físico, mental, moral, espiritual e social, em condições de liberdade e de dignidade, bem como o desenvolvimento de programas de assistência integral à saúde da criança, do adolescente e do jovem é um dever do estado".

No mesmo sentido, o ECA determina que a efetivação de direitos da criança é dever da família, da comunidade, do poder público e da sociedade em geral, especialmente no que pertine à vida, à saúde, à alimentação e à dignidade, conforme disposto em seu artigo $4^{\circ}$, de modo a assegurar o princípio da proteção integral da criança. Por evidente que tanto a Constituição Federal quanto o ECA não fazem qualquer distinção entre filhos de detentas ou de mulheres livres, sendo responsabilidade do Estado garantir, no ambiente prisional, as condições mínimas para o desenvolvimento sadio destas crianças.

A proteção especial atribuída às crianças está em consonância com o princípio da proteção integral, que atribui proteção absoluta às crianças em razão da sua peculiar condição de pessoas em desenvolvimento, o que demanda cuidados específicos e especial proteção por parte do Estado e de toda a sociedade (CUSTÓDIO, 2008, p. 32).

Para Oliveira, Beithum e Lima, o princípio da proteção integral há de ser compreendido como:

O complexo de direitos e garantias endereçado com exclusividade à criança e ao adolescente, que, na condição de pessoas em desenvolvimento, apresentam-se como titulares de direitos específicos e peculiares, sem prejuízo de todos os demais direitos fundamentais garantidos à pessoa humana em sede constitu- 
cional. Significa dizer que, devido à sua condição de pessoas em desenvolvimento, as crianças e os adolescentes figuram em posição de absoluta ou relativa dependência, necessitando, portanto, de cuidados e proteção peculiares (2011, p. 185).

A proteção integral da criança abarca também a prioridade para a elaboração de políticas públicas, bem como tomada de decisões a respeito da destinação de recursos, que, de acordo com o ECA, devem visar ao desenvolvimento sadio e harmonioso às crianças e adolescentes, em condições dignas de existência. Assim, além do aleitamento materno e do convívio familiar, condições adequadas de habitação e de vivência da mãe e do bebê são essenciais para a concretude da dignidade da pessoa humana, direito consagrado como um dos fundamentos do Estado Democrático de Direito, conforme o artigo $1^{\circ}$, III, da Constituição Federal. A dignidade humana é assegurada, ainda, pelo ECA, que garante à criança o gozo de todos direitos fundamentais inerentes à pessoa humana em condições de liberdade e de dignidade, conforme art. $3^{\circ}$ da referida lei.

Assim, o direito ao aleitamento materno e o direito à convivência familiar se consubstanciam em garantias humanitárias e, portanto, condições essenciais para uma vida digna. Outrossim, possuem relação intrínseca com a realização e o exercício de outros direitos (SEFFRIN e CENCI, 2017), especialmente nas áreas da infância, que demandam atenção especial do Estado para a concretização da proteção integral da criança.

De acordo com Viera, a execução penal retira da "criança encarcerada" o direito a uma infância protegida e, por esta razão, a autora formula algumas políticas públicas que poderiam melhorar o acolhimento das crianças nos estabelecimentos prisionais, evitando que a pena ultrapasse da pessoa condenada e se estenda para a criança, tais como:

Reformas legislativas; estabelecimento de normas e diretrizes sobre a idade limite de permanência de uma criança junto à mãe que cumpre pena de prisão, o que, para, ela não pode ficar aquém de três anos; elaboração de diretrizes voltadas ao processo de separação entre mãe e seu filho; reconhecimento de que o direito da mãe presa deve conjugar-se com o direito das crianças a uma vida digna, ao desenvolvimento integral, sem sofrerem com os estigmas e condições de privação de liberdade; efetivação das garantias legais pela inter-relação das políticas sociais de proteção infantoadolescente, da mulher, da saúde e da educação no contexto da execução penal; readequação dos espaços de atendimento infantil e regulamentação da etapa de educação infantil em ambiente prisional, reafirmando os pilares das funções assistenciais, pedagógicas e socializadoras (2013, p. 375).

A posição do Estado na garantia de direitos se vincula necessariamente a uma atuação positiva, utilizando-se de instrumentos político-administrativos para a implementação de projetos de voltados à maternidade (DAMMSKI, 
2019 , p. 07), em especial, para a melhoria das condições de aleitamento e convívio familiar no cárcere.

A melhoria nas condições carcerárias, portanto, depende de ações governamentais eficientes, que assegurem os direitos humanos e proporcionem o desenvolvimento da proteção integral, da saúde e da dignidade da criança e de sua genitora (PAIXÃO e FERREIRA, 2012, p. 07).

\section{Considerações finais}

Apesar de o direito à amamentação no cárcere ser um direito humano fundamental, as mulheres encarceradas e seus filhos têm seus direitos violados cotidianamente em razão da ausência de políticas públicas adequadas para este segmento da sociedade. A atuação estatal, no caso das mulheres encarceradas e de seus filhos, tem sido efetuada de forma excessivamente simplista, de modo a mitigar o princípio da proteção integral da criança, inviabilizando o acesso a condições mínimas de segurança e salubridade aptas ao desenvolvimento infantil.

A promoção da maternidade no cárcere demanda a transformação das unidades prisionais, tanto nos aspectos arquitetônicos quanto nos procedimentos de rotina, de modo a possibilitar o mínimo de dignidade para a genitora e para a criança, especialmente nos primeiros e mais importantes meses de vida.

Para a efetivação de políticas voltadas à maternidade no cárcere é necessária, por parte do Estado, a adoção de uma postura proativa e verdadeiramente interessada nos resultados de suas políticas públicas, primando sua atuação com relação a este segmento da sociedade pela observância do princípio do melhor interesse da criança, a fim de propiciar um desenvolvimento adequado para o bebê e prevenir a violação de direitos.

O Estado, portanto, tem um papel essencial na concretização de direitos humanos, devendo adotar uma conduta ativa para garantir o desenvolvimento sadio e harmonioso das crianças, por meio de condições dignas de existência, conforme os postulados do Estatuto da Criança e do Adolescente e demais normas previstas no ordenamento jurídico brasileiro e em compromissos internacionais.

\section{Referências}

ABRINQ, Fundação. Cenário da infância e adolescência no Brasil, 2019. Disponível em: <https://www.fadc.org.br/ sites/default/files/2019-05/cenario-brasil-2019.pdf> Acesso em: 10 mar. 2020.

ABRINQ, Fundação. A Criança e o Adolescente nos ODS: Marco zero dos principais indicadores brasileiros - ODS 1, 2, 3 e 5, 2017. Disponível em: <http://www.crianca.mppr.mp.br/arquivos/File/publi/abrinq/crianca_e_ adolescente_nos_ods_1_2_3_5_abrinq_2017.pdf> Acesso em: 10 maio. 2020.

ACNUDH, Alto Comissariado das Nações Unidas para os Direitos Humanos. Pacto Internacional sobre os Direitos Econômicos, Sociais e Culturais. In: Compilação de instrumentos internacionais de direitos 
humanos, 2011. Disponível em: <http://acnudh.org/wp-content/uploads/2011/06/Compilation-of-HRinstruments-and-general-comments-2009-PDHJTimor-Leste-portugues.pdf> Acesso em: 13 mar. 2020

ANTONINI, Lisliê Carvalho. Cárcere feminino, direito à amamentação e a Lei $\mathbf{n}^{\circ} \mathbf{1 1 . 9 4 2 / 2 0 0 9}$ à luz dos princípios da humanidade e da pessoalidade da pena. Porto Alegre, 2014. Dissertação (Mestrado em Ciências Criminais) - Faculdade de Direito, Pontifícia Universidade Católica do Rio Grande do Sul - PUCRSP.

ARMELIN, Bruna Dal Fiume. Filhos do cárcere: estudo sobre as mães que vivem com seus filhos em regime fechado. Revista da Graduação, Rio Grande do Sul, v. 03, n. 02, 2010.

BRASIL. Constituição (1988). Constituição da República Federativa do Brasil. Brasília, DF.

BRASIL. Lei n. 7.210, de 11 de Julho de 1984. Lei de Execução Penal. Brasília, DF.

BRASIL. Lei n. 8.069, de 13 de julho de 1990. Estatuto da Criança e do Adolescente. Brasília, DF.

BRUSCATO, Andrea Cristiane Maraschin; RANGEL, Ana Cristina. Desafios da educação de crianças que residem com suas mães em unidade prisional: o papel da Universidade e do poder público. Revista Educação, Santa Maria, v. 40, n. 02, p. 401-412, maio/agosto. 2015.

CARNEIRO, Zaira Severino; VERÍSSIMO, Maria de Lá Ó Ramallo. Gestação e desenvolvimento de bebês em situação de cárcere. Revista Extensão em Ação, Fortaleza, v. 2, n. 11, p. 39-49, jul./out. 2016.

CNJ, Conselho Nacional de Justiça. Série Tratados Internacionais de Direitos Humanos: Regras de Bangkok regras das Nações Unidas para o tratamento de mulheres presas e medidas não privativas de liberdade para mulheres infratora, 2019. Disponível em: <https://www.cnj.jus.br/wp-content/uploads/2019/09/ cd8bc11ffdcbc397c32eecdc40afbb74.pd f> Acesso em: 15 mar. 2020.

CNPCP, Conselho Nacional de Política Criminal e Penitenciária. Resolução n 14, de 11 de Novembro de 1994. Disponível em: <http://www.crpsp.org.br/interjustica/pdfs/regras-minimas-para-tratamento-dos-presosno-brasil.pdf> Acesso em: 02 fev. 2020.

CUSTÓDIO, André Viana. Teoria da proteção integral: pressuposto para compreensão do direito da criança e do adolescente. Revista do Direito, Santa Cruz do Sul, n. 29, p. 22-43, jan./jun. 2008.

DALMÁCIO, Laura Machado; CRUZ, Edson Júnior Silva da; CAVALCANTE, Lilia leda Chaves. Percepções de mães encarceradas sobre o direito à amamentação no sistema prisional. Revista Brasileira de História \& Ciências Sociais, Rio Grande, v. 06, n. 11, p. 54-72, jul. 2014.

DAMMSKI, Luiz Paulo. Processos de elaboração de políticas públicas como instrumento de efetivação de direitos e desenvolvimento. In: Integração Regional e Desenvolvimento na América do Sul: a IIRSA como pivô da implementação de políticas públicas transnacionais financiadas com recursos públicos. Curitiba, 2019. Dissertação (Mestrado em Direito) - Centro Universitário Autônomo do Brasil.

DIAS, Carla Aliny Peres; BRAZ, Virgínia Lara Bernardes. Direito à amamentação no cárcere: efetividade do artigo 5, inciso I, da Constituição Federal de 1988. Disponível em: <http://www.uit.br/mestrado/images/ publicacoes/V_Seminrio_Internacional_de_Processo_Novembro_2017_vol_2.pdf\#page=97> Acesso em: 20 jan. 2020.

FREIRE, Gruchenhka Oliveira Baptista. Cárcere e maternidade: o desafio de conciliar custódia e amamentação. Belém, 2017. Dissertação (Mestrado em Segurança Pública) - Instituto de Filosofia e Ciências Humanas, da Universidade Federal do Pará. p. 26.

GOMINHO, Dorcas Luisa Barretto. Amamentação no cárcere: vínculos e rupturas, 2016. Disponível em: <http:// www.psicopatologiafundamental.org.br/uploads/files/VII\%20CON GRESSO/ANAIS/Mesas\%20 redondas/22.2\%20PUBLICAR.pdf> Acesso em: 18 mar. 2020.

LEAL, Géssica Aline Dos Santos. Responsividade materna durante o banho e amamentação: análise da interação mãe-bebê no cárcere. Belém, 2018. Dissertação (Mestrado em Teoria e Pesquisa de Comportamento) - Universidade Federal do Pará.

MJSP, Ministério da Justiça e Segurança Pública: Departamento Penitenciário Nacional. Levantamento Nacional de Informações Penitenciárias, 2019. Disponível em: <https://app.powerbi.com/view?r=eyJrljoiZTk3ZTdmMDEtMTQxZS00YmExLWJhNWYtMDA5ZTIINDQ5NjhlliwidCI6ImViMDkwNDIwLTQ0NGMtNDNmNy05MWYyLTRIOGRhNmJmZThIMSJ9> Acesso em: 01 mar. 2020.

MJSP, Ministério da Justiça e Segurança Pública: Departamento Penitenciário Nacional. Levantamento Nacional de 
Informações Penitenciárias - INFOPEN MULHERES, 2018. 2. ed. Disponível em: <http://depen.gov.br/ DEPEN/depen/sisdepen/infopen-mulheres/infopenmulheres_arte_07-03-18.pdf> Acesso em: 11 mar. 2020.

MS, Ministério da Saúde. II Pesquisa de Prevalência de nas Capitais Brasileiras e Distrito Federal, 2009. Disponível em: <https://bvsms.saude.gov.br/bvs/publicacoes/pesquisa_prevalencia_aleitamento_materno. pdf $>$ Acesso em: 10 maio. 2020.

MS, Ministério da Saúde. Saúde da criança: aleitamento materno e alimentação complementar, 2015. Disponível em: <https://bvsms.saude.gov.br/bvs/publicaco es/saude_crianca_aleitamento_materno_cab23.pdf> Acesso em: 10 maio. 2020.

OLIVEIRA, Caroline Gazzola Subtil de; BEITHUM, Danielly Fernanda; LIMA, Dianne Trindade. O direito fundamental à saúde e o princípio da proteção integral da criança e do adolescente. Revista de Direito Público, Londrina, v. 06, n. 02, p. 184-201, ago./set. 2011.

UNICEF, Fundo das Nações Unidas para a Infância. Convenção sobre os Direitos da Criança, 1990. Disponível em: <https://www.unicef.org/brazil/convencao-sobre-os-direitos-da-crianca> Acesso em: 10 abr. 2020.

ONU, Organização das Nações Unidas. Regras das Nações Unidas para o tratamento de mulheres presas e medidas não privativas de liberdade para mulheres infratoras (Regras de Bangkok), 2010. Disponível em: <https://carceraria.org.br/wp-content/uploads/2012/09/Tradu\%C3\%A7\%C3\%A3on\%C3\%A3o-oficial-das-Regras-de-Bangkok-em-11-04-2012.pdf> Acesso em: 12 mar. 2020.

PAIXÃO, Adriano Nascimento; FERREIRA, Taissa. Determinantes da Mortalidade Infantil no Brasil. Informe Gepec, Toledo, v. 16, n. 2, p. 6-20, jul./dez. 2012.

SEFFRIN, Geciana; CENCI, Daniel Rubens. Dignidade da pessoa humana e direito à moradia digna no estado democrático de direito, 2017. Disponível em: <https://publicacoeseventos.unijui.edu.br/index.php/ direitoshumanosedemocracia/article/view/8678> Acesso em: 01 fev. 2020.

VIEIRA, Cláudia Maria Carvalho do Amaral. Crianças encarceradas: a proteção integral da criança na execução penal feminina da pena privativa de liberdade. 508 f. Florianópolis, 2013. Tese (Doutorado em Direito) Universidade Federal de Santa Catarina.

WHO, World Health Organization. Guideline: protecting, promoting and supporting breastfeeding in facilities providing maternity and newborn services, 2017. Disponível em: <https:// apps.who.int/iris/bitstream/handle/10665/259386/9789241550086-eng.pdf;jsessionid $=273947686$ E0D449E8E027EE3D00A98B0?sequence=1> Acesso em: 20 mar. 2020.

ZANINELLI, Giovana. Mulheres encarceradas: Dignidade da pessoa humana, gênero, legislação e políticas públicas. Jacarezinho, 2015. Dissertação (Mestrado em Direito) - Centro de Ciências Sociais Aplicadas, Universidade Estadual do Norte do Paraná. 